\title{
Urgencia 0 atención inmediata: una pequeña diferencia
}

\author{
F. Sánchez Perales \\ Pediatra. Servicio de Pediatría, Hospital Infanta Elena. Valdemoro, Madrid. España.
}

Rev Pediatr Aten Primaria. 2009; I :57 I-3

Fernando Sánchez Perales, fsperales@gmail.com

La "emergencia médica" o "urgencia médica" se define como una lesión o enfermedad que supone una amenaza inmediata para la vida de una persona y cuya asistencia no puede ser demorada'. Esta definición simple y concisa recogida de un medio tan popular como la Wikipedia sería suficiente para establecer una forma racional de la atención urgente, ya sea en Atención Primaria (AP) o en el ámbito hospitalario, puesto que si se aplicara, se dejarían de considerar como tales un gran número de las consultas que se demandan como urgentes.

Pero si a esta definición le vamos añadiendo matices, podremos empezar a entender en qué se ha convertido la asistencia urgente en la actualidad; por ejemplo, según el American College of Emergency Medicine, una emergencia es toda circunstancia nueva o inesperada que modifica la condición habitual de salud de una persona, que siendo reconocida por el paciente o por terceros, es percibida como potencialmente peligrosa ${ }^{2}$. Es decir, sólo con la introducción del concepto de que esa "circunstancia nueva o inesperada" es percibida "por el paciente o por terceros" se empieza a entender una parte importante del problema actual de la atención urgente, sobre todo si transformamos el que "plantea una amenaza para la vida" de la primera definición en que es "potencialmente" peligrosa de la segunda.

Existen numerosas publicaciones internacionales sobre el uso de los servicios de urgencias. En general se puede hacer extensivo a la situación en Pediatría de AP, que puede ser analizada utilizando un esquema basado en factores predisponentes (predisposición para utilizar los servicios), como la edad, el sexo, la raza, la educación, el número de miembros de la 
familia o la actividad laboral; factores facilitadores (capacidad para obtenerlos), como la accesibilidad geográfica, administrativa, temporal o cultural (este último resulta de gran importancia en estos momentos); y, por último, factores de necesidad (nivel de enfermedad y estado de salud percibido) ${ }^{3}$.

La suma de todos estos factores ha derivado en la situación actual, donde la urgencia hospitalaria se ha convertido en un servicio gratuito de consulta " 24 horas", en la cual el concepto de "situación súbita que supone una amenaza para la vida" es sustituido por el de "posibilidad de consultar cualquier situación en el momento en que la población lo demande, independientemente de la gravedad", poniendo los servicios sanitarios al mismo nivel que cualquier otro tipo de servicios. Más aún, como un bien más de consumo: "si necesito un refresco a las tres de la madrugada puedo adquirirlo en una tienda 24 horas" y, por tanto, "si tengo una indisposición, aunque sea leve, y no dispongo de otro momento para consultar o me resulta más cómodo (o accesible) hacerlo en este momento, pues se puede realizar".

En Atención Primaria el problema resulta más grave todavía, dado que habitualmente no existen profesionales exclusivos para atender las situaciones urgentes, y son los pediatras, con consultas ya generalmente saturadas, quienes deben suspender en ese momento su actividad asistencial prevista para atender la supuesta urgencia en un tiempo limitado y determinado.

Este hecho podría aceptarse si la urgencia fuera entendida según su concepto primitivo, el de una "situación amenazante para la vida", puesto que se produciría de forma ocasional o casi anecdótica en el ámbito de la AP. Sin embargo, actualmente, y de forma generalizada, la atención urgente en AP se hace equiparable a la consulta sin cita previa, lo que desemboca en situaciones tan incongruentes como la de oír en las salas de espera de los centros de salud: "yo es que me he citado por urgencias", o incluso suele suceder que cuando la población demanda asistencia en ese momento, desde las unidades administrativas se sugiere: "pues para que le atiendan ahora, pase por urgencias" (se considera la urgencia un coladero fácil o incluso pícaro).

Una vez más, los profesionales estaríamos en condiciones de adecuar y reorganizar esta asistencia si nos pidieran opinión $\mathrm{y}$, sobre todo, si tuviéramos las herramientas adecuadas, que no se basan únicamente en medios físicos o costosos materiales. 
Si realmente entendemos como una urgencia un hecho inesperado y que supone un riesgo para la vida, claramente se podrá desgajar de la AP dicha actividad y pasaría a quedar claro a la población que todo paciente que acude a un centro de salud sin cita previa podrá ser atendido o no en función de la causa de la consulta. Y dejaremos para la verdadera urgencia todas aquellas situaciones que por cercanía no han podido llegar a los servicios de urgencia hospitalarios pero que, indefectiblemente, tras las primeras medidas, serán trasladadas por los servicios de emergencia al hospital más cercano tras su estabilización. Por otra parte, se deben establecer las medidas necesarias para asegurar que las demandas de la población sean atendidas en el tiempo más razonable posible mediante la adecuación de los cupos, la flexibilidad de las agendas, etc.

Todo esto se enmarca dentro de las características de nuestro Sistema Nacional de Salud, que actualmente se ha visto afectado por la acción de los políticos hasta el punto de haberse convertido en insostenible desde la perspectiva financiera ${ }^{4}$, ofreciendo a la población una asistencia sanitaria sin límites que da todo a todo el mundo en cada momento, sin ningún coste, y que conduce a un uso inadecuado, cuando no a un abuso, de los servicios sanitarios.

\section{Bibliografía}

1. Wikipedia. Medicina de emergencia [consultado el 15/12/2009]. Disponible en http://es.wi kipedia.org/wiki/Urgencia_médica

2. Fiorentino JA. Servicios de urgencia ¿todo es urgente? SAMCT [consultado el 15/12/2009]. Disponible en www.samct.org.ar/comites/pe diatr/sdurgen.doc
3. Sánchez López J, Bueno Cavanillas A. Factores asociados al uso inadecuado de un servicio de urgencias hospitalario. Emergencias. 2005;17: 138-44.

4. Fundación de Estudios de Economía Aplicada. Impulsar un cambio posible en el sistema sanitario. Fedea McKinsey Company [consultado el 15/12/2009]. Disponible en www.cambioposi ble.es/documentos/sanidad_cambio_posible.pdf 